\title{
YOUTUBE: HERRAMIENTA EN LA FORMACIÓN PROFESIONAL POR LA IDENTIDAD Y LA SENSIBILIDAD SOCIAL
}

\author{
Luz Flor de María Ramírez Ojeda \\ Universidad Ricardo Palma
}

\begin{abstract}
RESUMEN
En el presente artículo, compartiremos una síntesis de nuestra investigación monográfica sobre el uso de YouTube en la formación profesional en pregrado, con el valor agregado de la sensibilización de los futuros profesionales con las poblaciones denominadas vulnerables y la imprescindible inclusión del tema transversal de identidad nacional en el currículum universitario. Esta idea surgió en el grupo en el que participamos bajo nuestros roles de docente y estudiantes en el Taller de Métodos de Estudio Universitario, asignatura que forma parte del Programa de Estudios Básicos de nuestra Universidad Ricardo Palma. En dicho Taller, una de las estrategias es el uso de la herramienta de YouTube, entre otras de corte tecnológico.
\end{abstract}

PALABRAS CLAVE

YouTube / Poblaciones vulnerables / Comunidades nativas peruanas / Formación profesional.

\begin{abstract}
In this article, we will share a summary of our monographic research on the use of YouTube in undergraduate education, with the added value of sensitizing future professionals about the called vulnerable populations and the essential inclusion of the transverse theme of national identity in the university curriculum. This idea arose in a group in which we participated on our roles as teacher and students in the Universitary Workshop in Study Methods, a subject included in the Basic Studies Program of our University Ricardo Palma. In this workshop, one strategy is to use YouTube as a tool, among other technological-based.
\end{abstract}

\section{KEY WORDS}

YouTube / Vulnerable populations / Peruvian native communities / Professional education 
La formación profesional, en nuestro siglo, constituye un reto a la creatividad y capacidad resolutiva docente. La distancia entre la forma, contenido y recursos con y cómo se formó a un educador de carrera o de alguna otra especialidad que hoy forma a otros futuros profesionales es amplia, y uno de los factores que ha creado esa brecha lo constituye el manejo de las Tecnologías de la Información y la Comunicación (TIC): «Existe un desfase entre la potencialidad de las TIC incorporadas en las aulas y la escasa renovación de los procesos pedagógicos. Las TIC se han ido incorporando en nuestras universidades, a menudo asociadas a prácticas docentes directivas y poco participativas. (Esteves, 2009, p. 60).

Ya Guarín (2001), definía a las TIC de la siguiente manera:

son el conjunto de recursos tecnológicos que permiten la adquisición, producción, almacenamiento, tratamiento, comunicación, registro y presentación de informaciones, en forma de voz, imágenes y datos contenidos en señales de naturaleza acústica, óptica o electromagnética que pueden mejorar la vida de todos los habitantes del planeta (p. 38)

que, como sabemos, han impactado -y siguen haciéndolo- en todos los aspectos de la vida humana, al punto de parecer inimaginable el acontecer diario sin ellas una vez que se las ha conocido. Así que el ámbito de la formación profesional tiene que considerarlas sin lugar a dudas.

Dentro de este mundo tecnológico Youtube, un sitio web -fundado en el 2005, en California (EE. UU.), por Chad Hurley, Steve Chen y Jawe Karim- de intercambio de videos, que permite a sus usuarios publicar en su plataforma archivos de video con fines diversos, a excepción de los videos ofensivos o ilegales, además de cómo menciona Educause Learning Initiative (2006) «que los usuarios posteen y etiqueten videos que son posteados por otros usuarios, también permite comentar videos, buscar contenido con palabras claves o por categorías, y crear o participar de grupos» (p.1), en nuestra opinión constituye una herramienta clave en la formación superior, es decir, en la preparación de futuros profesionales.

YouTube tiene varias características a su favor: es de fácil acceso y sencillo de usar; gratuito, pues las personas que quieran convertirse en usuarios, solo deben registrarse y crear su perfil o canal de videos. Hema Yoganarasimhan afirmaba en el 2012 que «YouTube es la tercera red social 
en línea más popular del mundo (después de Facebook y MySpace). En cuestión de funcionalidad, se asemeja a otras redes, sumando la ventaja de la función de "compartir video"» (p. 114) y este sitial se confirmó el 27 de setiembre el 2013 cuando el CLPT ${ }^{1}$ anunció su listado "top" de herramientas de aprendizaje 2013 y lo ubicó en el tercer lugar, después de Twitter y Google Drive/Docs.

Las ventajas descritas de YouTube pueden ampliarse pedagógicamente a un ámbito trascendental en la formación de todo profesional y que es la del rescate de poblaciones vulnerables. La sensibilización social que toda persona que va formándose en determinada carrera debe adquirir es un aspecto clave, y Youtube se constituye en un auxilio pertinente para el docente de Educación Superior en esta tarea.

\section{YOUTUBE Y LA ARQUITECTURA DE COMUNIDADES ANCES- TRALES Y POBLACIONES VULNERABLES}

La arquitectura es toda aquella obra de arte que es capaz de causar un fenómeno de emoción con el propósito de conmover al hombre mediante el espíritu de la intención, la cual se obtiene de un orden que es más que simple creación y reflejo del espíritu de los verdaderos arquitectos que a través de las formas afecta intensamente nuestros sentidos provocando así en nosotros emociones nunca antes sentidas al percibir una obra de arte funcional.

Por medio de esta relación, espíritu-emoción, somos capaces de percibir la belleza arquitectónica, la cual despierta una serie de resonancias internas en nosotros. A esto podemos definirlo como "emoción arquitectónica" que es el adecuado estado de equilibrio procedente de las compensación, simetría, percepción y armonía otorgadas por el acto de diseñar que desencadena en una serie de relaciones emotivas y conmovedoras.

Cuando una obra arquitectónica solo responde a una necesidad funcional, únicamente satisface la parte funcional de nuestro espíritu. Sin embargo, cuando produce relaciones sensibles podemos decir que satisface todo nuestro espíritu porque su creador dejó su propio espírtitu en ella. Y qué mejor ejemplo para representar todo lo antes mencionado que la obra de Ibuku en la comunidad de Ayung.

1 CLPT: Centre for Learning and Performance Technologies 
Una vez superada la idea de que las tradiciones constructivas ancestrales eran sinónimo de arquitecturas vetustas y perecederas, los arquitectos contemporáneos, cada vez con mayor frecuencia, tienen en cuenta los mejores recursos y cualidades de las arquitecturas ancestrales que si bien en sus orígenes fueron creados mediante el conocimiento empírico por los habitantes de las comunidades, han demostrado gran eficiencia y una mejor adaptación a las necesidades de la población en general y al medio ambiente. (Artiles y Sangabriel, 2012, p. 96).

Este es el momento donde entra a tallar la importancia de YouTube aprovechando su característica de medio audiovisual de gran impacto a nivel global. Si empleamos esta gran herramienta que nos brinda la tecnología, podríamos generar una gran revolución en torno a la difusión y mejoramiento de estos conocimientos ancestrales, más aún si consideramos que pueden referirse a comunidades que se encuentran en situación de riesgo o vulnerabilidad, con la consecuente posible generación de acciones a su favor.

\section{IBUKU Y SU GRAN APORTE A LA COMUNIDAD DE AYUNG}

$I b u k u^{2}$ es un grupo de jóvenes arquitectos, liderados por Elora Hardy, especializados en el desarrollo de proyectos arquitectónicos sustentables donde el único material que es utilizado es el bambú por considerarlo un material que además de ser bello, es muy resistente, flexible y que, a diferencia de la madera, puede obtenerse sin dañar al medio ambiente, ya que su ciclo de crecimiento es de solamente cuatro años. (Hardy, 2012, 2:49-3:42). Asimismo, Ibuku emplea las distintas técnicas y sistemas constructivos de la comunidad de Ayung, ubicada a orillas del río del mismo nombre, en la isla de Bali, Indonesia.

Aunque el bambú se ha utilizado tradicionalmente en todo el continente asiático en estructuras de corta vida, Ibuku lo han combinado con nuevos métodos de tratamiento para que pueda tener un mayor tiempo de duración. Una de las características más interesantes del proceso de trabajo de $I b u k u$ es que no solo diseñan y construyen sino que integran en estas actividades a las personas de la comunidad de Ayung, ya sea como personas activas en las actividades antes mencionadas o mano de obra artesanal.

2 Ibuku: Ibu significa madre y $k u$ significa mí; palabras del idioma indonesio. Por lo tanto Ibuku en conjunto significa Mi madre. 


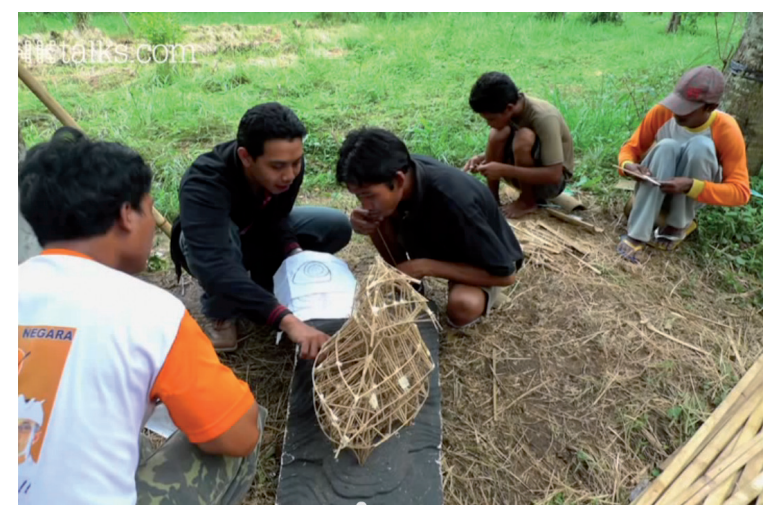

Figura $\mathrm{N}^{\circ} 1$ : Trabajo en conjunto con la comunidad de Ayung Fuente: https://www.youtube.com/watch?v=XOSQksSlr9c\#t=424

El proyecto co-realizado en la comunidad de Ayung es la denominada "Green Village” (Villa Verde). Este proyecto comprende casas edificadas de acuerdo a las necesidades sociales de la comunidad así como también a los contornos naturales del terreno, aprovechando las vistas hacia el río y los volcanes de Bali. El concepto fue generar espacios confortables para los habitantes en los que la gente pueda disfrutar de su entorno natural. Asimismo, existe un número de casas, dentro de la comunidad, que están destinadas hacia el ecoturismo ${ }^{3}$, de esta manera la comunidad puede generar sus propios recursos económicos en base a sus propias actividades.

Finalmente, es gracias al aporte de Ibuku que la comunidad de Ayung ha podido ver nuevas oportunidades que les han servido para dejar de ser considerada como una comunidad vulnerable, gracias a la utilización de sus conocimientos que fueron adecuados a nuestra era y difundidos a nivel global por medios audiovisuales como YouTube.

3 Ecoturismo: Son actividades turísticas enfocadas a la sustentabilidad, la preservación, la apreciación del medio (tanto natural como cultural) que acoge y sensibiliza a los viajantes. 


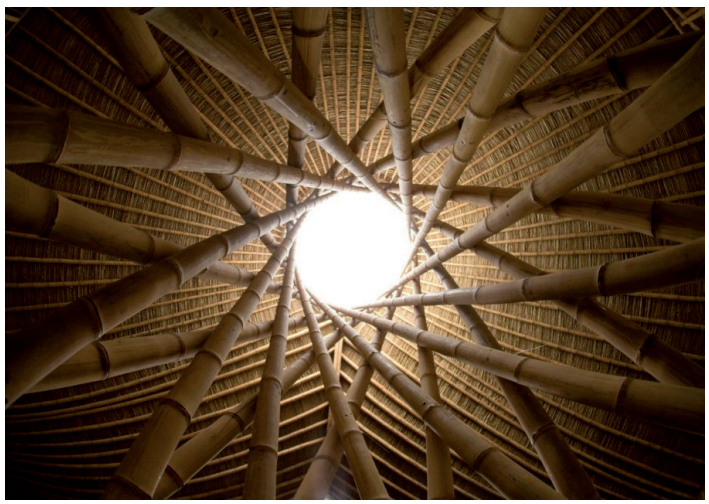

Figura $\mathrm{N}^{\circ} 2$ : Vista interior del techo.

Fuente: http://ibuku.com/

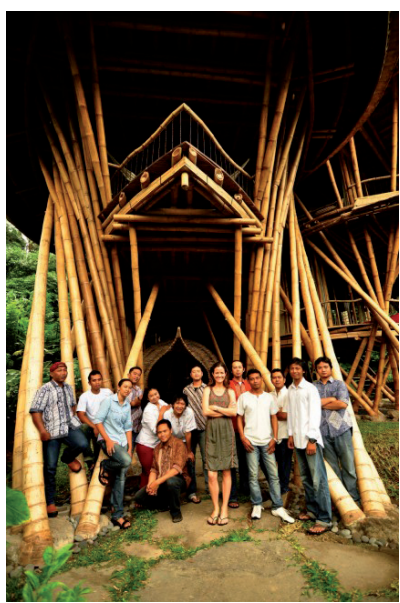

Figura $\mathrm{N}^{\circ}$ 3: Ibuku y algunos de los miembros de la comunidad de Ayung Fuente: http://ibuku.com/about/our-team/

YOUTUBE Y LAS LENGUAS DE COMUNIDADES ANCESTRALES Y POBLACIONES VULNERABLES

Perú es un país que se caracteriza por ser pluricultural. Muchas culturas coexisten bajo el territorio peruano y, cada una con sus particularida- 
des, contribuye a hacer del Perú una nación rica por su heterogeneidad en gastronomía, recursos, lenguas, etc. El Perú cuenta con aproximadamente «1,786 comunidades indígenas, ubicadas en 11 departamentos, [que] fueron identificadas geográfica y cartográficamente en los censos nacionales 2007: XI de Población y II de Comunidades Indígenas» (Nomberto, 2011, párr. 1).

Con referencia a las lenguas, según el Ministerio de Educación, (DIGEIBIR) (2014) «en el Perú se hablan $47^{4}$ lenguas indígenas pertenecientes a 19 familias lingüísticas [...] 37 lenguas originarias actualmente extintas, con lo que el número de lenguas indígenas que se hablaron en nuestro país subiría a 84» (párr.1). Sin embargo, ¿son estas lenguas verdaderamente protegidas por el Estado? Muchas de las lenguas del Perú corren peligro de desaparición siendo expresión de la cultura de una sociedad.

Para ilustrar esta situación, podemos citar datos de la UNESCO (2010): «Entre las lenguas que se consideran seriamente en peligro y en situación crítica de extinción, figuran en Argentina son 6, Belice 1, Bolivia 18, Brasil 64, Costa Rica 4, Chile 4, Colombia 24, Ecuador 8, El Salvador 1, Honduras 5, Guatemala 3, México 53, Nicaragua 4, Panamá 2, Paraguay 6, Perú 29, Uruguay 1, y Venezuela 15» (párr. 4).

Si bien, actualmente hay algunas políticas públicas que colaboran con la preservación de estas lenguas, como el registro que viene haciendo el MINEDU desde el 2012 de los niños con lengua materna diferente al español que van a escuelas públicas más los docentes que se necesitan para dichos centros educativos, la propuesta curricular y la producción de materiales pedagógicos en siete lenguas originarias desde el 2013 por ejemplo (rutas de aprendizaje, cuadernos de trabajo, bibliotecas), podemos plantearnos la pregunta y decir ¿Qué podemos hacer los demás en general?

A continuación, presentaremos un ejemplo que es símbolo de lo que se puede hacer para luchar por la continuidad y la preservación de las lenguas peruanas, en alianza con entidades que se preocupan por estos temas y utilizando la herramienta que nos ocupa: YouTube.

4 Según Moseley (2010) en el Atlas Interactivo UNESCO de las lenguas del mundo en peligro, de 62 idiomas que registra para el Perú: 10 se encuentran en nivel vulnerable, 18 definitivamente en peligro de extinción, 14 grave peligro de extinción, 10 en peligro crítico, 5 en nivel de extinto. 


\section{La comunidad Kukama}

"Kumbarikira...

Ser Kukama es un arte,

Un arte ancestral

Que nos identifica de nuestro origen maternal

Qué orgullo es ser Kukama

Y queremos hacer más conocida nuestra lengua original...”

Así dice la letra de la canción "Kumbarikira", cantada por niños de la comunidad Kukama, en el distrito de Nauta, en el departamento de Loreto. Se sabe que en esta comunidad, «la emisora radial Ucamara comenzó el proyecto Icuari, una escuela que trata de recuperar la lengua indígena, 6 ancianos se turnan para dar clases a 12 niños y niñas que aprenden dicha lengua a través de cuentos y canciones» (Napa, 2013. párr. 2).

A través de un video subido en la red YouTube, estos niños cantan en español y en su lengua materna, invitando a los usuarios a interesarse por la lengua "Kukama". Los Kukama-Kukamiria pertenecen a la familia lingüística Tupi Guaraní, y es uno de los pueblos que pertenece a la Amazonía peruana. A pesar de tener mucha presencia en la zona, el uso de su lengua materna ha quedado relegado y se encuentra en estado crítico y en peligro de extinción.

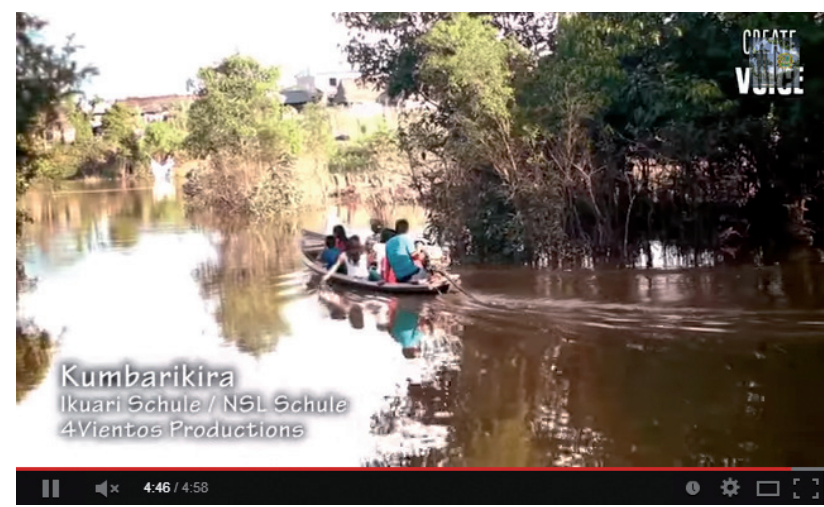

Figura $\mathrm{N}^{\circ}$ 4: Imagen del videoclip, niños cantando la canción "Kumbarikira"

Fuente: https://www.youtube.com/watch?v=O3C-18Nf_Aw 
Este proyecto realizado en alianza con la asociación "Create your Voice" y Radio Ucamara, buscó mostrarle al mundo que en el Perú existen muchas lenguas, que no son tomadas en cuentas por el Estado, y que necesitan de apoyo para poder salir de la actual situación de diglosia en la que se encuentran.

La diglosia es «Bilingüismo, en especial cuando una de las lenguas goza de prestigio o privilegios sociales o políticos superiores» (http://lema. rae.es/drae/?val=diglosia). En Perú, el español desplaza a las variedades de lenguas maternas, incluso, en los pueblos más alejados de nuestro país, hay pocos maestros que puedan enseñar en las comunidades ancestrales, en la lengua materna-indígena que corresponda.

Según OEI (2014):

La UNESCO todavía recomendó en 1953 que < el mejor medio para la enseñanza de un niño es su lengua materna>, igualmente en el contexto peruano tanto su Constitución Política de 1979 -que en su artículo $35^{\circ}$ estipulaba que $<$ el Estado promueve el estudio y conocimiento de las lenguas aborígenes. Garantiza el derecho de las comunidades quechua, aymara y demás comunidades nativas a recibir educación en su propia lengua $>-$, como la Constitución Política de 1993 señala en su artículo $17^{\circ}$ que "fomenta la educación bilingüe intercultural, según las características de cada zona. Preserva las diversas manifestaciones culturales y lingüísticas del país”. (párr.8).

Sin embargo, se conoce que en nuestro país existe todavía la preocupante situación en la que en algunos lugares las lenguas indígenas son reprimidas y hasta prohibidas.

A pesar de tratarse de sociedades eminentemente quechuohablantes, los actores de la educación operan en escuelas que usan el castellano como lengua de enseñanza, y están inmersos en programas diseñados de manera general para todo el país sin considerar de manera real y efectiva las particularidades de sus escenarios. Así, en Tayacaja no existe ni siquiera experimentalmente ningún programa de educación bilingüe ni intercultural. Al contrario, aun cuando hay profesores bilingües (por ser de extracción andina) en los centros educativos, el uso del quechua está prohibido y hasta reprimido. Por otro lado, las expresiones culturales locales, incomprendidas en su lógica y racionalidad, son objeto de burla, crítica y, a veces, de desprecio por parte de los agentes educativos, especialmente por aquellos que provienen de las ciudades y que son nomolingües castellanos. (OEI, párr. 18). 
Proponemos a YouTube como una plataforma y ventana al mundo, en donde las asociaciones culturales, estudiantiles y público en general, en colaboración con las comunidades ancestrales, se preocupen y unan esfuerzos para transmitir por medio de videos la realidad de una población en peligro, pero muy rica en conocimiento y cultura, apoyándose en su beneficio de ser -como ya se ha mencionado- una plataforma gratuita, sencilla de usar, y ofrecer facilidades para transmitir gracias a un "link", la dirección virtual del video para compartirlo con el mundo.

Finalmente, es importante también colaborar con la difusión de iniciativas como la de "Create your Voice" y el video de Kumbarikira, y en ese sentido, todos podemos ser agentes de cambio. El uso de todas las herramientas que tengamos a mano, de forma positiva e innovadora, será la respuesta al deterioro en el que la sociedad se sumerge día a día. Aun cuando muchas personas se oponen al uso de las TIC, estas pueden resultar positivas si se les da el uso apropiado. Compartir videos como el citado está al alcance de un click de mouse nuestro a nuestros contactos, pero el efecto puede suscitar una reacción social trascendental.

\section{OTRAS COMUNIDADES HERMANAS ANCESTRALES}

Así como en el caso presentado Cocama, en líneas siguientes compartiremos algunos de los enlaces a videos de YouTube que abordan contenidos sobre nuestras etnias originarias:

\begin{tabular}{|c|c|c|c|}
\hline CULTURA & TÍTULO & ENLACE/DURACIÓN & SÍNTESIS \\
\hline JAQARU & $\begin{array}{c}\text { Cultura } \\
\text { peruana. } \\
\text { Jaqaru } \\
\text { Parte } 1 . \\
\text { Lengua } \\
\text { que se } \\
\text { apaga }\end{array}$ & $\begin{aligned} & \text { https://www.youtube.com/ } \\
& \text { watch? } \mathrm{v}= \text { RyZSwpPRtlQ } \\
&(9: 25) \\
& \text { Parte 2: https://www.youtube.com/ } \\
& \text { watch? }=\text { LoJcsgBOZbA } \\
&(9: 02) \\
& \text { Parte 3: https://www.youtube.com/ } \\
& \text { watch? }=\text { cgCq5ihYilk } \\
&(8: 09)\end{aligned}$ & $\begin{array}{l}\text { Documental etnográ- } \\
\text { fico, acerca de la co- } \\
\text { munidad de Tupe, en } \\
\text { Yauyos-Lima. Trata } \\
\text { sobre la lengua origi- } \\
\text { nal de Tupe, el Jaqaru y } \\
\text { su actual situación, así } \\
\text { como las costumbres } \\
\text { de la comunidad. }\end{array}$ \\
\hline
\end{tabular}

5 Hemos seleccionado videos que registran el asentamiento de estas comunidades en la parte territorial peruana; sin embargo, en algunos casos, solo encontramos videos producidos por países con los que compartimos fronteras y tienen presencia de las mismas etnias. También notamos la falta de material sobre etnias y lenguas como: wampis, jeberos, urarina, cashauita, ocaina, munichi, chamicuro, pacaraos, resigaro, vacacocha, zaparo, panobo, yameo, culle. 


\begin{tabular}{|c|c|c|c|}
\hline \multirow[t]{2}{*}{ QUECHUA } & $\begin{array}{c}\text { Repor- } \\
\text { taje: El } \\
\text { Quechua } \\
\text { en el Perú }\end{array}$ & $\begin{array}{c}\text { https://www.youtube.com/ } \\
\text { watch?v=DHiqGiOsGtE } \\
(12: 42)\end{array}$ & $\begin{array}{l}\text { Reportaje con opinio- } \\
\text { nes de la lingüista Ma- } \\
\text { ritza Valle, congresista } \\
\text { Hilaria Supa, prof. De- } \\
\text { metrio Yupanqui, ci- } \\
\text { neasta Flaviano Quispe }\end{array}$ \\
\hline & $\begin{array}{l}\text { Himno } \\
\text { Nacional } \\
\text { del Perú }\end{array}$ & $\begin{array}{c}\text { https://www.youtube.com/watch?v } \\
\text { =xWKolvsm7gY\&list=PLBLrfNr } \\
\text { 7bZiw5_6e-3dRAeOgbP07_BXsq } \\
(3: 12)\end{array}$ & $\begin{array}{l}\text { Letra en quechua. Vo- } \\
\text { ces infantiles. }\end{array}$ \\
\hline \multirow{4}{*}{ AYMARA } & $\begin{array}{l}\text { Himno } \\
\text { Nacional } \\
\text { del Perú }\end{array}$ & $\begin{array}{c}\text { https://www.youtube.com/ } \\
\text { watch?v=iJ5I_KMleZc } \\
(4: 16)\end{array}$ & $\begin{array}{l}\text { Por INDEPA. Voz fe- } \\
\text { menina. }\end{array}$ \\
\hline & Lenguas & $\begin{array}{c}\text { https://www.youtube.com/ } \\
\text { watch?v=ntVUDnSg0LM } \\
(10: 32)\end{array}$ & $\begin{array}{l}\text { La historia de una anciana, } \\
\text { Manuela, y la discrimina- } \\
\text { ción que sufre por no hablar } \\
\text { castellano, así como su re- } \\
\text { flexión para que no se pier- } \\
\text { da el idioma aymara. }\end{array}$ \\
\hline & $\begin{array}{c}\text { Poesía en } \\
\text { Aymara }\end{array}$ & $\begin{array}{c}\text { https://www.youtube.com/ } \\
\text { watch?v=EpibkFp1wFc }(0: 54)\end{array}$ & $\begin{array}{l}\text { Poesía en este idioma } \\
\text { en voz de una niñita } \\
\text { muy pequeña. }\end{array}$ \\
\hline & $\begin{array}{c}\text { Mito } \\
\text { Aymara } \\
\text { (Perú)- } \\
\text { Origen de } \\
\text { la quinua- } \\
\text { Corto } \\
\text { animado }\end{array}$ & $\begin{array}{c}\text { https://www.youtube.com/ } \\
\text { watch?v=02ZjiMB72Ko (4:18) }\end{array}$ & $\begin{array}{l}\text { Leyenda aymara de } \\
\text { cómo una estrella ben- } \\
\text { dijo al pueblo aymara } \\
\text { con el "grano dorado". }\end{array}$ \\
\hline PUKINA & $\begin{array}{c}\text { 1.Des- } \\
\text { apari ción } \\
\text { y super- } \\
\text { vivencia } \\
\text { del } \\
\text { idioma } \\
\text { Pukina } \\
\end{array}$ & $\begin{array}{c}\text { https://www.youtube.com/ } \\
\text { watch? }=\mathrm{rN} 810 \mathrm{bY} 79 \mathrm{NI} \\
(59: 10) \\
\text { Parte } 2 \text { https://www.youtube.com/ } \\
\text { watch?v }=62 \mathrm{fti} \text { n6AYU } \\
(24: 44)\end{array}$ & $\begin{array}{l}\text { Conferencia de Thérè- } \\
\text { se Bouysse-Cassagne } \\
\text { (Instituto Francés de } \\
\text { Estudios Andinos - } \\
\text { IFEA) }\end{array}$ \\
\hline \multirow[b]{2}{*}{ AWAJÚN } & $\begin{array}{l}\text { Himno } \\
\text { Nacional } \\
\text { del Perú }\end{array}$ & $\begin{array}{c}\text { https://www.youtube.com/ } \\
\text { watch?v=r63gcWhK3o0 } \\
(3: 19)\end{array}$ & $\begin{array}{l}\text { Por INDEPA. Voz de } \\
\text { hombre adulto. Subti- } \\
\text { tulado en español. }\end{array}$ \\
\hline & $\begin{array}{l}\text { Estilo } \\
\text { Awajún }\end{array}$ & $\begin{array}{c}\text { https://www.youtube.com/ } \\
\text { watch?v=PeNxR_G5tp0 } \\
(30: 36)\end{array}$ & $\begin{array}{l}\text { Lengua, actividades de la } \\
\text { comunidad, costumbres, } \\
\text { conocimientos ancestra- } \\
\text { les. Preocupaciones. }\end{array}$ \\
\hline $\begin{array}{l}\text { ASHÁ- } \\
\text { NINKA }\end{array}$ & $\begin{array}{l}\text { Himno } \\
\text { Nacional } \\
\text { del Perú }\end{array}$ & $\begin{array}{c}\text { https://www.youtube.com/ } \\
\text { watch?v=X0LtIYJ0LWE } \\
(3: 48)\end{array}$ & $\begin{array}{l}\text { Por INDEPA. Voz fe- } \\
\text { menina adulta. }\end{array}$ \\
\hline
\end{tabular}




\begin{tabular}{|c|c|c|c|}
\hline $\begin{array}{l}\text { ASHÁ- } \\
\text { NINKA }\end{array}$ & $\begin{array}{l}\text { Los As- } \\
\text { háninkas } \\
\text { en la sel- } \\
\text { va ama- } \\
\text { zónica } \\
\text { peruana }\end{array}$ & $\begin{array}{c}\text { https://www.youtube.com/ } \\
\text { watch?v=F-iHE2B1j6s } \\
(9: 52)\end{array}$ & $\begin{array}{l}\text { Fotografías de las ca- } \\
\text { racterísticas de la co- } \\
\text { munidad con fondo de } \\
\text { cantos asháninkas. }\end{array}$ \\
\hline BORA & $\begin{array}{c}\text { Traditio- } \\
\text { nal Bora } \\
\text { dances }\end{array}$ & $\begin{array}{c}\text { https://www.youtube.com/ } \\
\text { watch?v=FisDtCiW7r0 } \\
(6: 40)\end{array}$ & $\begin{array}{l}\text { Algunas danzas canta- } \\
\text { das y bailadas por un } \\
\text { grupo de boras }\end{array}$ \\
\hline MATSÉS & $\begin{array}{l}\text { Los Mat- } \\
\text { sés de } \\
\text { Perú }\end{array}$ & $\begin{array}{c}\text { https://www.youtube.com/ } \\
\text { watch?v=nrRVOaldXaU } \\
(12: 57)\end{array}$ & $\begin{array}{l}\text { Lengua, actividades de } \\
\text { la comunidad, costum- } \\
\text { bres. }\end{array}$ \\
\hline NANTI & $\begin{array}{l}\text { Amazon } \\
\text { tribes, jun- } \\
\text { gle Peru } \\
\text { natives, } \\
\text { contacted } \\
\text { Indig- } \\
\text { enous. } \\
\text { Nativos } \\
\text { selva } \\
\text { amazó- } \\
\text { nica }\end{array}$ & $\begin{array}{c}\text { Parte 1: https://www.youtube.com/ } \\
\text { watch?v=ZEeGCRdhtOM } \\
(10: 00) \\
\text { Parte 2: (aparece grupo Nanti) } \\
\text { https://www.youtube.com/watch?v } \\
\text { =qm7BzqpDs10\&list=PLE45EB4 } \\
\text { E2B006C534 } \\
(10: 03)\end{array}$ & $\begin{array}{l}\text { Por INDEPA. Carac- } \\
\text { terización del Área de } \\
\text { Reserva Territorial en } \\
\text { contacto inicial: Kuga- } \\
\text { pakori Nahua Nanti. Da- } \\
\text { tos generales e históricos } \\
\text { de las comunidades nati- } \\
\text { vas: explotación sufri- } \\
\text { da, censo, actividades, } \\
\text { lengua, servicios que se } \\
\text { implementan en el plan } \\
\text { de protección de INDE- } \\
\text { PA, así como las impli- } \\
\text { cancias de los contactos } \\
\text { con personas foráneas a } \\
\text { la comunidad. }\end{array}$ \\
\hline ACHUAR & $\begin{array}{l}\text { Himno } \\
\text { Nacional } \\
\text { del Perú } \\
\end{array}$ & $\begin{array}{c}\text { https://www.youtube.com/ } \\
\text { watch?v=xO-n2LfHFno } \\
(2.36)\end{array}$ & $\begin{array}{l}\text { Traducción del R. P. } \\
\text { Luis Bola. }\end{array}$ \\
\hline $\begin{array}{l}\text { CANDO- } \\
\text { SHI }\end{array}$ & $\begin{array}{c}\text { Parla- } \\
\text { metrics: } \\
\text { Candos- } \\
\text { hi-Shapra } \\
\text { I }\end{array}$ & $\begin{array}{c}\text { https://www.youtube.com/ } \\
\text { watch?v=6AQmcBxoeQc (2:08) }\end{array}$ & $\begin{array}{l}\text { Audio de canción "Ca- } \\
\text { tatúa", en lengua Can- } \\
\text { doshi }\end{array}$ \\
\hline CASHIBO & $\begin{array}{l}\text { El que } \\
\text { me sigue }\end{array}$ & $\begin{array}{c}\text { https://www.youtube.com/ } \\
\text { watch?v=} \begin{aligned} \text { PIDP1L8cWw } \\
(2: 39)\end{aligned}\end{array}$ & $\begin{array}{l}\text { Documental. Un sabio an- } \\
\text { ciano indígena y un joven } \\
\text { lingüista de campo luchan } \\
\text { por preservar la lengua } \\
\text { y la cultura del pueblo } \\
\text { kakataibo. A pesar de las } \\
\text { grandes diferencias y las } \\
\text { muchas dificultades, sur- } \\
\text { ge entre ellos una entraña- } \\
\text { ble amistad. }\end{array}$ \\
\hline
\end{tabular}




\begin{tabular}{|c|c|c|c|}
\hline $\begin{array}{c}\text { CASHINA- } \\
\text { HUA }\end{array}$ & $\begin{array}{l}\text { Música } \\
\text { Kaxi- } \\
\text { nawa }\end{array}$ & $\begin{array}{c}\text { https://www.youtube.com/ } \\
\text { watch?v=GKD4G-1I9m0 } \\
(2: 12)\end{array}$ & $\begin{array}{l}\text { Canción de adoración } \\
\text { al Señor en esta len- } \\
\text { gua. Video subido por } \\
\text { André Menezes. }\end{array}$ \\
\hline PURÚS & $\begin{array}{l}\text { Lenguas } \\
\text { Purús }\end{array}$ & $\begin{array}{c}\text { https://www.youtube.com/ } \\
\text { watch?v= } \\
(13: 23)\end{array}$ & $\begin{array}{l}\text { Muestra de las accio- } \\
\text { nes de normalización } \\
\text { de lenguas de pueblos } \\
\text { originarios en la ama- } \\
\text { zonia peruana por el } \\
\text { MINEDU a través de } \\
\text { la Dirección General } \\
\text { de Educación Intercul- } \\
\text { tural Bilingüe y Rural; } \\
\text { Sharanahua, Culina o } \\
\text { Madija y Cashinahua, o } \\
\text { Huni Kuin. }\end{array}$ \\
\hline HUITOTO & $\begin{array}{l}\text { Santiago } \\
\text { y Rember } \\
\text { Yahuar- } \\
\text { cani, }\end{array}$ & $\begin{array}{c}\text { Clan Aymenu (artistas plásticos } \\
\text { amazónicos) } \\
\text { https://www.youtube.com/ } \\
\text { watch?v=hh6Kx_0ZKTk (7:01) } \\
\text { https://www.youtube.com/ } \\
\text { watch?v=jvKP1mu1kxA (2:37) }\end{array}$ & $\begin{array}{l}\text { Muestras plásticas del } \\
\text { reconocido pintor hui- } \\
\text { toto Rember Yuyarcani. }\end{array}$ \\
\hline $\begin{array}{l}\text { MACHI- } \\
\text { GUENGA }\end{array}$ & $\begin{array}{l}\text { Mashi- } \\
\text { guengas } \\
\text { en el } \\
\text { Manu }\end{array}$ & $\begin{array}{c}\text { https://www.youtube.com/ } \\
\text { watch?v=IatNnN4zkJ8 } \\
(3: 10)\end{array}$ & $\begin{array}{l}\text { Video de Discovery. } \\
\text { com. Reconocimiento } \\
\text { del conocimiento de } \\
\text { los beneficios medici- } \\
\text { nales de las plantas en } \\
\text { el Manu, de los mashi- } \\
\text { guengas. } \\
\text { Vr también "Koga- } \\
\text { pakoris 3", en https:// } \\
\text { www.youtube.com/ } \\
\text { watch? v=S Fku- } \\
\text { gaR5pnY (7:27) }\end{array}$ \\
\hline SHIPIBO & $\begin{array}{l}\text { Shipibo- } \\
\text { La pelí- } \\
\text { cula de } \\
\text { nuestra } \\
\text { memoria } \\
(2011) \\
\text { Trailer- } \\
\text { Docu- } \\
\text { mental }\end{array}$ & $\begin{array}{c}\text { https://www.youtube.com/ } \\
\text { watch?v= } \\
(8: 53)\end{array}$ & $\begin{array}{l}\text { Opinión de pobladores } \\
\text { de la comunidad shipiba } \\
\text { después de ver la pelí- } \\
\text { cula, rescatando el valor } \\
\text { de la misma como testi- } \\
\text { monio de sus orígenes y } \\
\text { muestra de su decisión } \\
\text { de conservar sus conoci- } \\
\text { mientos ancestrales. }\end{array}$ \\
\hline
\end{tabular}




\begin{tabular}{|c|c|c|c|}
\hline & $\begin{array}{l}\text { Himno } \\
\text { Nacional } \\
\text { del Perú }\end{array}$ & $\begin{array}{c}\text { https://www.youtube.com/ } \\
\text { watch?v=rolFJZYfAqU }(0: 52)\end{array}$ & $\begin{array}{l}\text { Cantado por los niños } \\
\text { de san Francisco, Uca- } \\
\text { yali }\end{array}$ \\
\hline SHIPIBO & $\begin{array}{c}\text { Cantos } \\
\text { shipibos, } \\
\text { cantos de } \\
\text { las telas- } \\
\text { kene- } \\
\text { Herlinda } \\
\text { Agustín. } \\
\text { wmv }\end{array}$ & $\begin{array}{c}\text { https://www.youtube.com/ } \\
\text { watch?v=xvGq-KnPPKg } \\
(3: 03)\end{array}$ & $\begin{array}{l}\text { Cantos que solo las } \\
\text { mujeres shipibas pue- } \\
\text { den hacer, interpretan- } \\
\text { do los símbolos de las } \\
\text { telas. }\end{array}$ \\
\hline SECOYA & $\begin{array}{l}\text { La agri- } \\
\text { cultura } \\
\text { Secoya }\end{array}$ & $\begin{array}{c}\text { https://www.youtube.com/ } \\
\text { watch?v=iTIBS9LQ7Pc } \\
(1: 59: 19)\end{array}$ & $\begin{array}{l}\text { Película del antropó- } \\
\text { logo Jorge Gasché. } \\
\text { Fonds National Suisse } \\
\text { de la Recherche Scien- } \\
\text { tifique, Berne et Centre } \\
\text { National de la Recher- } \\
\text { che Scientifique, Paris. } \\
\text { Muestra las labores del } \\
\text { proceso hortícola du- } \\
\text { rante un año. }\end{array}$ \\
\hline \multirow[b]{2}{*}{ TICUNA } & $\begin{array}{l}\text { Los ticu- } \\
\text { nas }\end{array}$ & $\begin{array}{c}\text { https://www.youtube.com/ } \\
\text { watch?v=Vjj8I6CH1Yg (1:11) }\end{array}$ & $\begin{array}{l}\text { Brevísima reseña de } \\
\text { actividades económi- } \\
\text { cas y ubicación de esta } \\
\text { etnia. }\end{array}$ \\
\hline & $\begin{array}{l}\text { Danzas } \\
\text { y cantos } \\
\text { ances- } \\
\text { trales de } \\
\text { la etnia } \\
\text { Tikuna } \\
\end{array}$ & $\begin{array}{c}\text { https://www.youtube.com/ } \\
\text { watch?v=PiJYt0U2T } 88 \\
(5.15)\end{array}$ & $\begin{array}{l}\text { Muestra de una danza } \\
\text { y canto por un grupo } \\
\text { de ticunas. }\end{array}$ \\
\hline YAGUA & $\begin{array}{l}\text { Los ya- } \\
\text { guas }\end{array}$ & $\begin{array}{c}\text { https://www.youtube.com/ } \\
\text { watch?v=vqyhwDeKrmA } \\
(2: 36)\end{array}$ & $\begin{array}{l}\text { Por INDEPA. Lengua, } \\
\text { actividades y costum- } \\
\text { bres de esta etnia. }\end{array}$ \\
\hline \multirow[b]{2}{*}{ YINE } & Los yines & $\begin{array}{c}\text { https://www.youtube.com/ } \\
\text { watch?v=E9M7O_kkVUk } \\
(2: 39)\end{array}$ & $\begin{array}{l}\text { Por INDEPA. Caracte- } \\
\text { rización de los yines o } \\
\text { piros. }\end{array}$ \\
\hline & $\begin{array}{c}\text { Mayta } \\
\text { Capac } \\
\text { Alatrista/ } \\
\text { Yines- } \\
\text { Cos- } \\
\text { tumbres } \\
\text { ancestra- } \\
\text { les }\end{array}$ & $\begin{array}{c}\text { https://www.youtube.com/ } \\
\text { watch? } \mathrm{v}=\mathrm{Fa} \text { [0Hz_9NSM } \\
(2: 16)\end{array}$ & $\begin{array}{l}\text { Por INDEPA. Simbo- } \\
\text { logía de los rituales de } \\
\text { la pintura y otros ritua- } \\
\text { les de iniciación. }\end{array}$ \\
\hline
\end{tabular}




\begin{tabular}{|c|c|c|c|}
\hline $\begin{array}{l}\text { HARAKM- } \\
\text { BUT }\end{array}$ & Fotos & $\begin{array}{c}\text { https://www.youtube.com/ } \\
\text { watch?v=LUG4rjy6Yfg }(5: 11)\end{array}$ & $\begin{array}{l}\text { Texto inicial infor- } \\
\text { mativo y fotos de este } \\
\text { pueblo. }\end{array}$ \\
\hline $\begin{array}{l}\text { AMAHUA- } \\
\text { CA }\end{array}$ & $\begin{array}{l}\text { Ama- } \\
\text { huaca's } \\
\text { song }\end{array}$ & $\begin{array}{c}\text { https://www.youtube.com/ } \\
\text { watch?v=eOCLimxngCU (1:16) }\end{array}$ & $\begin{array}{l}\text { Audio de canción en } \\
\text { amahuaca. }\end{array}$ \\
\hline $\begin{array}{l}\text { SHARANA } \\
\text { HUA }\end{array}$ & $\begin{array}{l}\text { Sharana- } \\
\text { huas }\end{array}$ & $\begin{array}{l}\text { Parte } 1 \text { : https://www.youtube.com/ } \\
\text { watch?v=7IfEJAO6Apk (8:46) } \\
\text { Parte } 2: \text { https://www.youtube.com/ } \\
\text { watch?v=QPGK0fTGcbQ }(8: 08)\end{array}$ & $\begin{array}{l}\text { Misioneros dominicos } \\
\text { presentan este video } \\
\text { que caracteriza de for- } \\
\text { ma detallada a esta } \\
\text { etnia, con respetoy evi- } \\
\text { dente admiración. }\end{array}$ \\
\hline \multirow{3}{*}{ YANESHA } & $\begin{array}{l}\text { Indios- } \\
\text { Yanesha- } \\
\text { FECO- } \\
\text { NAYA- } \\
\text { Perú }\end{array}$ & $\begin{array}{c}\text { https://www.youtube.com/ } \\
\text { watch?v=i0H7BCyM5T0 } \\
(3: 48)\end{array}$ & $\begin{array}{l}\text { Líderes hablan de su } \\
\text { labor como represen- } \\
\text { tantes. Culmina con un } \\
\text { canto yanesha. }\end{array}$ \\
\hline & $\begin{array}{c}\text { Kosha- } \\
\text { mñats } \\
\text { anets } \\
\text { Yanesha } \\
\text { (Danzas } \\
\text { del pueblo } \\
\text { Yanesha) }\end{array}$ & $\begin{array}{c}\text { https://www.youtube.com/ } \\
\text { watch?v=s7EjO0Fn65s } \\
(5: 45)\end{array}$ & $\begin{array}{l}\text { Sabia del pueblo ex- } \\
\text { plica la necesidad de } \\
\text { transmtir los conoci- } \\
\text { mientos ancetrales a } \\
\text { las nuevas generacio- } \\
\text { nes. Muestra de danza } \\
\text { yanesha, cantada por } \\
\text { sus pobladores. }\end{array}$ \\
\hline & $\begin{array}{l}\text { Tiempo } \\
\text { de viaje- } \\
\text { Yanesha } \\
\text { selva } \\
\text { central } \\
(1 / 2)\end{array}$ & $\begin{array}{l}\text { https://www.youtube.com/ } \\
\text { watch?v=0AVKtLglBbY (10:13) } \\
\text { Parte } 2: \text { https://www.youtube.com/ } \\
\text { watch?v=Oo9aBHIXYvk }(10: 10)\end{array}$ & $\begin{array}{l}\text { Programa "Tiempo de } \\
\text { viaje". Situación actual } \\
\text { con las actividades de- } \\
\text { predadoras y no depre- } \\
\text { dadoras alrededor del } \\
\text { territorio donde está la } \\
\text { comunidad yanesha. } \\
\text { Caracterización de la } \\
\text { comunidad yanesha } \\
\text { que les dan ingresos } \\
\text { económicos. }\end{array}$ \\
\hline $\begin{array}{l}\text { YAMINA- } \\
\text { HUA }\end{array}$ & $\begin{array}{l}\text { Pueblos } \\
\text { indígenas } \\
\text { de Boli- } \\
\text { via Ya- } \\
\text { minahua, } \\
\text { Machi- } \\
\text { neri }\end{array}$ & $\begin{array}{c}\text { https://www.youtube.com/ } \\
\text { watch?v=y95Qe9MSr8U } \\
(1.51)\end{array}$ & $\begin{array}{l}\text { Caracterización gene- } \\
\text { ral de inicios y situa- } \\
\text { ción actual de estas } \\
\text { etnias. }\end{array}$ \\
\hline
\end{tabular}




\begin{tabular}{|c|c|c|c|}
\hline ANDOA & $\begin{array}{l}\text { El gran } \\
\text { paso } \\
\text { Andoa }\end{array}$ & $\begin{array}{c}\text { https://www.youtube.com/ } \\
\text { watch?v=imswmwtiYO0 (10:01) }\end{array}$ & $\begin{array}{l}\text { Diversas personas de } \\
\text { esta etnia y otras expli- } \\
\text { can características de la } \\
\text { comunidad, así como } \\
\text { su proceso histórico. }\end{array}$ \\
\hline OMAGUA & $\begin{array}{l}\text { Coniupu- } \\
\text { yara dub }\end{array}$ & $\begin{array}{c}\text { https://www.youtube.com/ } \\
\text { watch?v=Dvh9gbGbPBQ }(1: 31)\end{array}$ & $\begin{array}{l}\text { Asociación Coniupu- } \\
\text { yara (Grandes Muje- } \\
\text { res en idioma Oma- } \\
\text { gua) aquí nos enseñan } \\
\text { a contar en lengua } \\
\text { tupí guaraní 0magua } \\
\text { - Iquitos, casi extin- } \\
\text { to). Ver: https://www } \\
\text { youtube.com/watch } \\
\text { ?v=GR9aJEfqHB4 }\end{array}$ \\
\hline TAUSHIRO & $\begin{array}{l}\text { El último } \\
\text { Taushiro }\end{array}$ & $\begin{array}{l}\text { Parte } 1: \text { https://www.youtube.com/ } \\
\text { watch?v=tn9oRjT7X0I }(8: 13) \\
\text { Parte } 2: \text { https://www.youtube.com/ } \\
\text { watch? } \mathrm{v}=\text { T8VNOqKuZiw }(9: 12)\end{array}$ & $\begin{array}{l}\text { Programa "Cuarto Po- } \\
\text { der", edición de abri } \\
\text { de 2011. Testimonio } \\
\text { de Amadeo García, el } \\
\text { último Taushiro. }\end{array}$ \\
\hline & $\begin{array}{l}\text { Lengua } \\
\text { Muchik }\end{array}$ & $\begin{array}{c}\text { https://www.youtube.com/ } \\
\text { watch?v=qYKK7qks7Sg (5.41) }\end{array}$ & $\begin{array}{l}\text { Labor de la profesora } \\
\text { Ana Ramos en el res- } \\
\text { cate y enseñanza de la } \\
\text { lengua Muchik. }\end{array}$ \\
\hline MOCHICA & $\begin{array}{l}\text { Idioma } \\
\text { Muchik }\end{array}$ & $\begin{array}{c}\text { Parte I: } \\
\text { https://www.youtube.com/ } \\
\text { watch?v=YiKGu1j7ZkM (4:12) } \\
\text { Parte II: https://www.youtube. } \\
\text { com/watch?v=mUYeWV-weps } \\
(4: 11) \\
\text { Parte III: https://www.youtube. } \\
\text { com/watch?v=77RPP7_a9_c } \\
(3: 58)\end{array}$ & $\begin{array}{l}\text { Reportaje de cómo se } \\
\text { está rescatando, apren- } \\
\text { diendo y enseñando la } \\
\text { lengua Muchik gracias } \\
\text { a la profesora que na- } \\
\text { ció en Argentina, Ana } \\
\text { Ramos, que da clases } \\
\text { en Lambayeque. Inclu- } \\
\text { ye palabras y diálogos } \\
\text { en esta lengua. }\end{array}$ \\
\hline $\begin{array}{l}\text { COMUNI- } \\
\text { DA DES } \\
\text { NATIVAS } \\
\text { AISLADAS }\end{array}$ & $\begin{array}{l}\text { Comu- } \\
\text { nidades } \\
\text { nativas } \\
\text { aisladas } \\
\end{array}$ & $\begin{array}{c}\text { https://www.youtube.com/ } \\
\text { watch?v=j_NhdyHqHkM (3:29) }\end{array}$ & $\begin{array}{l}\text { Presencia de estas co- } \\
\text { munidades en la fron- } \\
\text { tera de Brasil y Perú. }\end{array}$ \\
\hline $\begin{array}{l}\text { MASHCO } \\
\text { PIRO }\end{array}$ & $\begin{array}{l}\text { Imágenes } \\
\text { inéditas } \\
\text { de indíge- } \\
\text { nas Mas- } \\
\text { hco Piro } \\
\text { que viven } \\
\text { en selva } \\
\text { de Perú }\end{array}$ & $\begin{array}{c}\text { https://www.youtube.com/ } \\
\text { watch?v=xZyQuxdUYQ8 (1:18) }\end{array}$ & $\begin{array}{l}\text { Video inédito de grupo } \\
\text { filmado, luego del en- } \\
\text { contrado en la frontera } \\
\text { con Brasil y Perú, aún } \\
\text { no contactado. }\end{array}$ \\
\hline
\end{tabular}




\section{YOUTUBE Y LA TECNOLOGÍA DE ANDENES INCAS: ARQUI- TECTURA E INGENIERÍA ANCESTRALES Y ASOCIATIVIDAD EN LOS NEGOCIOS NACIONALES Y GLOBALES}

La biodiversidad de nuestro país enlazada a la variedad geográfica que posee hizo que nuestros ancestros construyeran andenes. Por ejemplo, Protzen (2005) refiere los andenes de Ollantaytambo de la siguiente manera:

Los andenes son el símbolo del poderío humano sobre la naturaleza, de sus habilidades para reformar y transformar la tierra a su antojo. Los incas eran agricultores aventajados, con una herencia rica en el manejo de las plantas y sofisticadas técnicas de cultivo. Cook advirtió los ingeniosos diseños de los andenes. Los muros de contención estaban rellenos con dos capas distintas: una capa inferior de subsuelo artificial compuesto de piedras gruesas y arcilla, la que era cubierta a su vez con capas de tierra fina importada (1916:494). Al referirse a los andenes construidos bajo el gobierno de Pachakuti, Sarmiento de Gamboa enfatizaba que la mayor parte de la capa superficial usada para rellenar los andenes había sido acarreada desde lugares lejanos (1943 [1572]: cap. XXX, 92-93) [...]. Asimismo, la permeabilidad de los muros de los andenes permitía que el agua en exceso se filtre de andén en andén. Para ayudar a este flujo de agua entre andenes, los incas construían, con frecuencia, canales de desagüe al interior de los muros (p. 53).

APEGA, la Sociedad Peruana de Gastronomía nacida en el 2007, lanzó este año el proyecto “Adopta un Andén” para rescatar la productividad de los andenes peruanos objetivo relacionado al impulso que se le quería dar a los pequeños productores, vinculándolos con los demás agentes de la cadena gastronómica exitosa que hoy es un boom en el país: restaurantes, cadena de supermercados, comercializadores, público en general. Esta iniciativa se conoció por diversos medios, uno de ellos YouTube (www. youtube.com/watch?v=ELHmeuBQLQE). El 12 de setiembre del 2014, una pareja de agricultores, adultos mayores recibieron un premio vinculado a este proyecto, como se informa en la reseña del video en la página de Americatv.com.pe (2014):

Por restaurar parte de los andenes abandonados de Curibaya, en la sierra de Tacna, Clementina y Leandro Pinto recibirán este año el máximo galardón otorgado por Apega en Mistura, la feria más grande del país. No solo los restauraron sino que habilitaron su sistema de 
riego para producir, después de muchos años de abandono, hermosos frutos de la tierra. Hoy gozan de nueve meses de producción, y pueden combatir mejor las épocas de sequía. Los pobladores que emigraron en busca de oportunidades ahora están regresando puesto que todo el pueblo hoy está usando otra vez los viejos andenes (párr. -3).

Esta ha sido otra de las oportunidades que la herramienta que nos ocupa ha brindado, al servicio del rescate de los conocimientos de nuestras comunidades ancestrales, quedando así registrados por este medio masivo, listos para ser utilizados - entre otros usos- para la formación de los futuros profesionales de nuestro país.

\section{A MANERA DE CIERRE}

Sirva este texto para incentivar el uso de la plataforma You Tube como uno de los tantos recursos TIC que bien aprovechados, contribuyan a la formación académica de los futuros profesionales. También, como reflexión sobre aquello que estamos o no haciendo por nuestros hermanos que pertenecen a poblaciones que poseen un invalorable patrimonio cultural, en muchos casos con un serio riesgo de extinción. Además, para seguir reforzando nuestra autoestima como peruanos que permita empoderarnos como país, recuperando los valores de nuestras culturas milenarias que tanto necesitamos. Más aún, para recordar que la sensibilidad humana por el otro, otro ser humano, no es patrimonio de un sentimiento de una religión ni ideología determinadas, sino de la esencia de nuestra condición de personas.

Nos sentimos orgullosos de haber realizado un trabajo en conjunto: docente-estudiantes, como manifiesto de la misma esencia de los valores ancestrales de nuestras comunidades: la asociatividad, la colaboración, en conocimiento compartido como legado, en bien de causas mayores, por el bien de nuestra sociedad que, al fin y al cabo, es parte de una mayor: la sociedad del ser humano.

\section{REFERENCIAS BIBLIOGRÁFICAS}

\section{AMERICATV.COM.PE}

(31 de agosto de 2014). Mistura en las alturas. Recuperado el 31 de agosto de 2014, de http://www.americatv.com.pe/cuarto-poder/reportajes/ mistura-alturas-noticia-10128. 
ARTILES, D. y SANGABRIEL, A.

2012 Construyendo la vulnerabilidad: Un riesgo para todos. Arquitectura y Urbanismo, 33(2), 68-70.

ÁVILA, E.

2003 Las Nuevas Tecnologías de la Información y la Comunicación como herramientas necesarias en la formación profesional de los estudiantes universitarios.Etic@net, 1(1).

CARREÑO, P.

2014 Las lenguas originarias del Perú. Recuperado el 21 de mayo de 2014, de http://www.digeibir.gob.pe/articulos/las-lenguas-originarias-del-per $\% \mathrm{C} 3 \% \mathrm{BA}$

EDUCAUSE LEARNING INITIATIVE

20067 things you should know about...YouTube. Recuperado el 26 de mayo de 2014, de http://net.educause.edu/ir/library/pdf/ELI7018.pdf

ESTEVE, F.

2009 Bolonia y las TIC: de la docencia 1.0 al aprendizje 2.0. La Cuestion Universitaria 5 pp.59-68. Recuperado el 25 de mayo de 2014, de http://www.anobium.es/docs/gc_fichas/doc/LRSPFDzlbc.pdf

GUARÍN, A.M.

2001 Formación de técnicos e investigadores en Tecnologías de la Información. Madrid: Editorial Fundesco.

HARDY, E.

2012, 18 de abril Elora Hardy: Building a sustainable (bamboo) future. [Archivo de video]. Video publicado en https://www.youtube.com/ watch? $\mathrm{v}=\mathrm{XOSQksSlr9c \# t=424}$

2013, 6 de junio Elora Hardy Designing Green Village. [Archivo de Video]. Video publicado en http://vimeo.com/67853828

HART, J. (Comp.)

2014 Top 100 Herramientas para el aprendizaje 2013. Recuperado el 14 de mayo de 2014, de http://c4lpt.co.uk/top100tools/

MOSELEY, Christopher (ed.)

2010 Atlas de las lenguas del mundo en peligro. 3a. ed.. París: Ediciones 
UNESCO. Versión en línea: http://www.unesco.org/culture/en/ endangeredlanguages/atlas

NAPA

2013 Una alegre canción para la triste historia de Kukama. Disponible en http://napa.com.pe/2013/07/26/una-alegre-cancion-para-la-triste-historia-de-kukama/

NOMBERTO, V.

2011 Mapa etnolingüístico del Perú. Disponible en http://blog.pucp.edu. pe/item/136464/mapa-etnolinguistico-del-peru

ORGANIZACIÓN DE ESTADOS INTERAMERICANOS

(s.f.) La educación en castellano a poblaciones quechuas en los Andes peruanos. Disponible en http://www.rieoei.org/ oeivirt/rie16a08. $\mathrm{htm}$

PRENSKY, M.

2009 Why YouTube Matters. Recuperado el 26 de mayo de 2014, de http://www.marcprensky.com/writing/Prensky-Why_You_Tube_ Matters-01.pdf

PROTZEN, J.P.

2005 [1993] Arquitectura y construcción incas en Ollantaytambo. Trad. R. Valdez y S. Téllez. Lima: Pontificia Universidad Católica del Perú, Fondo Editorial.

RIVAS, P.

2014, 1 de marzo APEGA-Proyecto "Adopta un Andén" para rescatar la productividad de los andenes peruanos [video]. Recuperado el 20 de agosto de 2014, de https://www.youtube.com/ watch? $\mathrm{v}=\mathrm{ELHmeuBQLQE}$

RODRÍGUEZ, M.

2006 El perfil de competencias del informador profesional. Revista Española de Orientación y Psicopedagogía, 19(2), 235.239.

SÁNCHEZ, P.

s.f. Horizontes de Arquitectura. Recuperado el 05 de junio de 2014, de 
http://horizontes18.com/wordpress/wp-content/uploads/2013/09/ 69-20121.pdf

SPDA ACTUALIDAD AMBIENTAL

s.f. Loreto: niños buscan rescatar la lengua kukama con video "Kumbarikira". Disponible en http://www.actualidadambiental.pe/ $? \mathrm{p}=19824$

Unesco: 29 lenguas originarias peruanas permanecen en peligro de extinción. Disponible en http://www.actualidadambiental.pe/?p= 4206

YOGANARASIMHAN, H.

2012 Impact of Social Network Structure on Content Propagation: A study using YouTube data. Recuperado el 26 de mayo de 2014, de http://faculty.gsm.ucdavis.edu/ hema/youtube.pdf. http://lema.rae. es/drae/?val=diglosia

www.youtube.com

\section{Nota:}

El presente artículo ha sido escrito en colaboración con Luis Fernando Barriales Revilla, estudiante de la Facultad de Arquitectura y Urbanismo (URP) miembro de la agrupación de arte y arquitectura Waka Pacha donde ha participado en la elaboración de distintos proyectos; uno de ellos es el Manifiesto INKARRI, exhibido en el Museo de Sitio Arturo Jiménez Borja - Puruchuco, Parque Kennedy de Miraflores y en el Colegio de Arquitectos del Perú; y Astrid Desire Lozano Ueda, estudiante de Traducción e Interpretación en la Universidad Ricardo Palma, quien se especializa en inglés y chino. 